\title{
AA6061 Alaşımının Tornalanmasında Kesme Parametrelerinin Yüzey Pürüzlülüğü Üzerine Etkisinin Analizi ve Optimizasyonu
}

\author{
Barış ÖZLÜ,a, , Mahir AKGÜN ${ }^{\mathrm{a}}$, Halil DEMİR ${ }^{\mathrm{b}}$ \\ a,* Aksaray Üniversitesi Teknik Bilimler Meslek Yüksekokulu, AKSARAY 68100, TÜRKIYYE \\ ${ }^{b}$ Karabük Üniversitesi Teknoloji Fakültesi Imalat Mühendisliği Bölümü, KARABÜK 78050, TÜRKIYYE
}

MAKALE

BÍLGİSi

Alınma: 02.04.2019

Kabul: 31.07.2019

\section{Anahtar Kelimeler:}

AA 6061 ,

İşlenebilirlik,

Yüzey Pürüzlülüğü,

Optimizasyon

"Sorumlu Yazar:

e-posta:

barisozlu@aksaray.ed

\section{ÖZET}

Bu çalışmada, kaplamasız ve TiB2 kaplamalı kesici takımlar ile AA6061 alaşımının tornalanmasında yüzey pürüzlülüğü üzerinde kesme parametrelerinin etkileri deneysel olarak araştırıldı. İșleme deneyleri CNC torna tezgâhında soğutma sıvısı kullanılmadan gerçekleştirilmiştir. İşleme deneyleri kesici takım kaplaması ve kesme parametrelerinin farklı düzeylerinde Taguchi L18 $\left(2^{1} \times 3^{3}\right)$ dizinine göre tasarlanmıştır. İșleme deneyleri sonucunda elde edilen veriler istatiksel olarak analiz edilmiştir. En iyi işlenmiş yüzey pürüzlülüğü için optimum kesme parametrelerinin seviyeleri belirlenmiştir. Varyans analiz sonuçlarına göre ilerleme miktarı \% 64.28 katkı oranı ile yüzey pürüzlülügünü etkileyen en etkin faktör olmuştur.

https://dx.doi.org/10.30855/gmbd.2019.02.04

\section{Analysis and Optimization of Effects on Surface Roughness of Cutting Parameters on Turning of AA6061 Alloy}

\section{ARTICLE \\ INFO \\ Received: 02.04.2019 \\ Accepted: 31.07 .2019 \\ Keywords: \\ AA 6061 \\ Machinability, \\ Surface Roughness, \\ Optimization \\ "Corresponding \\ $\underline{\text { Authors }}$ \\ barisozlu@aksaray.ed}

\begin{abstract}
In this study, the effects of cutting parameters on surface roughness in turning of AA6061 alloy with uncoated and TiB2 coated cutting tools were investigated by experimental. The machining tests were carried on CNC turning without coolant. Machining tests were designed by the Taguchi L18 $\left(2^{1} \times 3^{3}\right)$ index at different levels of cutting tool coating and cutting parameters. The results obtained from cutting tests were analyzed statistically. The optimum level in cutting parameters is determined for the best-machined surface roughness (Ra). According to Anova analysis results, it has been determined that the most efficient parametric is feed rate by $64.28 \%$ on surface roughness.
\end{abstract}

https://dx.doi.org/10.30855/gmbd.2019.02.04 


\section{GİRIŞ (INTRODUCTION)}

Alüminyum alaşımları yüksek mukavemet, düşük yoğunluk, süneklik, tokluk ve yorulmaya karşı direnç gibi özellikleri nedeniyle otomotiv, uçak ve havacılık endüstrisinde mühendislik malzemesi olarak kullanılmaktadır. Bu malzemelerin işlenmesi kolay ve üstün işlenebilirlik yeteneğine sahiptirler [1-2]. 6xxx serisi alüminyum alaşımlar özellikle mukavemet, şekil verilebilirlik, kaynaklanabilirlik, korozyon direnci ve düşük maliyet gibi özelliklerinden dolayı diğer alüminyum serilerine göre daha fazla tercih edilmektedir [3].

Üretim endüstrisinde rekabet gücünün korunması için yüksek verimlilik ve yüksek kalitede ürünlerin üretilmesi sürekli rekabet gücünün artmasına neden olmaktadır. Üretim endüstrisinde, arzu edilen şekil ve ebatlarda demir ve demir dışı malzemelerin tornalama yöntemi ile şekillendirilmesi, önemli ve yaygın olarak kullanılan bir işleme sürecidir [4-6]. Yüzey pürüzlülüğü, tornalama işleminde iş parçasının kalitesini belirleyen en önemli özelliklerden biridir [7]. İşleme deneyleri genellikle maliyetli ve zaman alan işlemlerdir. Maliyeti ortadan kaldırmak ve zamanı azaltmak için bazı ileri teknikler geliştirilmiştir. Bunlara genellikle modelleme denir. Bazı modelleme yöntemleri vardır. Ampirik modelleme, analitik modelleme, mekanik modelleme, sonlu elemanlar modelleme ve yapay sinir ağı (YSA) modelleme bu modelleme yöntemlerinden bazılarıdır. Bu teknikler sayesinde, deneysel olarak elde edilen bazı sonuçlar kullanılarak tahminler yapılmaktadır [8]. Literatürde farklı alüminyum serilerinin işlenebilirliğinin belirlenmesi üzerine yapılan birçok çalışma vardır. Rajeswari ve Amirthagadeswaran yaptıkları çalışmada, farklı SiC takviye oranlarında üretilen $7075 \mathrm{Al}$ malzemesini freze tezgâhında işlemişlerdir. Farklı iş mili hızlarının, ilerleme miktarlarının, talaş derinliğinin ve malzeme yüzde ağırlık oranlarının RSM tabanlı gri ilişki analiz yöntemi ile yüzey pürüzlülüğü, kesme kuvveti ve takım aşınmaları üzerindeki etkilerini araştırmışlardır. Sonuçların analizinde en iyi işleme parametreleri olarak $1000 \mathrm{rpm}$ iş mili hızı, $0.03 \mathrm{~mm} / \mathrm{dev}$ ilerleme miktarı, $1 \mathrm{~mm}$ kesme derinliği ve ağırlıkça $\% \quad 5 \quad \mathrm{SiC}$ oranı olarak belirlemişlerdir [9]. Gonçalves ve Silva AA6351 (Al$\mathrm{Si}-\mathrm{Mg})$ alaşımına farklı oranlarda bakır $(\mathrm{Cu})$ eklenmesinin işlenebilirliğe etkisini araştırmışlardır. Alüminyum alaşımının işlenebilirliği matkap ile delme esnasında delme torku, itme kuvveti ve yüzey pürüzlülüğü ölçümleri ile değerlendirilmiştir. Kesme ve ilerleme miktarları beş farklı değerde seçilmiştir.
Sonuç olarak alüminyuma katılan bakırın çökelti sertleştirmesini artırdığını belirlemişlerdir. Delme deneylerinde ilerleme miktarının artması ile delme torku ve itme kuvveti doğrusal olarak artmıştır. Bakır oranı artan numunelerin delinmesinde $0.2 \mathrm{~mm} / \mathrm{dev}$ ilerleme miktarında daha yüksek delme torku ve itme kuvveti ölçülmüş bununla beraber delme sırasında yüzey pürüzlülüğü kötüleşmiştir [10]. Demir ve Gündüz 6061 Al alaşımının işlenebilirliği üzerine yapay yaşlandırmanın etkisini incelemişlerdir. $180^{\circ} \mathrm{C}$ 'de farklı yaşlandırma sürelerinin ve kesme hızlarının kesme kuvveti ve yüzey pürüzlülügüüne etkisini araştırmışlardır. Yaşlandırma süresinin ve kesme hızının yüzey pürüzlülük değerlerini önemli ölçüde etkilediğini belirlemişlerdir [3]. Ranganath ve diğerleri 6061 alüminyum alaşımının kuru kesme şartlarında kesme parametrelerinin yüzey pürüzlülüğü üzerine etkisini araştırmışlardır. Yüzey pürüzlülüğü üzerinde en etkili kesme parametresinin kesme hızının olduğunu tespit etmişlerdir. Kesme parametrelerinin optimum seviyeleri olan en düşük talaş derinliği ve ilerleme miktarında en düşük yüzey pürüzlülüğü değerini elde etmişlerdir [11].

Bu çalışmada, AA6061 alaşımının PVD yöntemi ile kaplanmış TiB2 kaplamalı ve kaplamasız karbür kesici takımlarla işlenmesi sonucunda oluşan yüzey pürüzlülüğü (Ra) üzerinde kesme parametrelerinin ve kesici takım kaplamasının etkisi analiz edilerek optimizasyonu yapılmıştır.

\section{MATERYAL VE YÖNTEM (MATERIAL AND METHOD)}

İşleme deneyleri, ticari olarak temin edilen T6 1s1l işlem uygulanmış AA 6061 alaşımı (Ø50x300 mm boyutlarında) üzerinde kuru kesme şartlarında $\mathrm{CNC}$ torna tezgahında gerçekleştirilmiştir. Tablo 1'de AA 6061 alüminyum alaşımının kimyasal analiz sonuçları yer almaktadır.

Tablo 1. AA 6061 alüminyum alaşımının \% kimyasal analiz sonuçları (\% Chemical analysis results of AA 6061 aluminum alloy)

\begin{tabular}{lllll}
\hline $\mathrm{Fe}$ & $\mathrm{Si}$ & $\mathrm{Cr}$ & $\mathrm{Mn}$ & $\mathrm{Al}$ \\
\hline 0.5 & $0.6-1.0$ & 0.1 & $0.2-0.8$ & Kalan \\
\hline $\mathrm{Mg}$ & $\mathrm{Zn}$ & $\mathrm{Cu}$ & $\mathrm{Ti}$ & Diğer \\
\hline $0.8-1.2$ & 0.25 & $0.6-1.4$ & 0.1 & 0.15 \\
\hline
\end{tabular}

Kesme deneylerinde PVD yöntemi ile kaplanmış TiB2 kaplamalı ve kaplamasız karbür kesici takımlar kullanılmıştır. Deneylerde kullanılan kesici takımlar TCGT 16T304HP10 formunda ve kalitesi üretici firma 
tarafindan KC5010 ve K313 olarak kodlanmıştır. Kesici takımlar STGCL 2020K16 kodlu takım tutucuya mekanik olarak bağlanmıştır. Şekil 1'de kesici takım ve takım tutucusunun formu görülmektedir. İşleme parametresi olarak üç farklı kesme hızı $(250,300$ ve $350 \mathrm{~m} / \mathrm{min})$, üç farklı ilerleme miktarı $(0.1,0.15$ ve $0.2 \mathrm{~mm} / \mathrm{dev})$ ve üç farklı talaş derinliğinde $(1, \quad 1.5$ ve $2 \mathrm{~mm})$ belirlenmiştir.

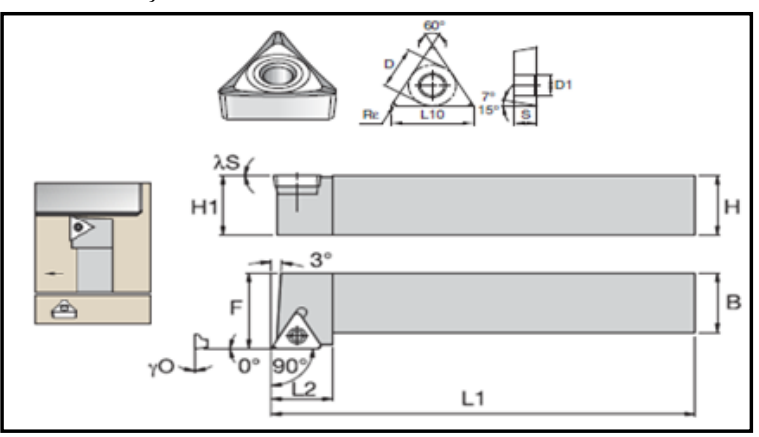

Şekil 1. Kesici takım ve takım tutucu (Cutting tool and tool holder)

Mahr Perthometer M1 model yüzey pürüzlülük test cihazı ile tornalama testi sonucu elde edilen yüzeyler üzerinde ölçümler yapılmıştır. Yüzey pürüzlülüğü $(\mathrm{Ra})$ her bir deney sonrası oluşan işlenmiş yüzeyler üzerinde üç farklı noktada yapılan ölçümlerin ortalamalarının hesaplanmasıyla ortalama yüzey pürüzlülüğü $(\mathrm{Ra})$ elde edilmiştir.

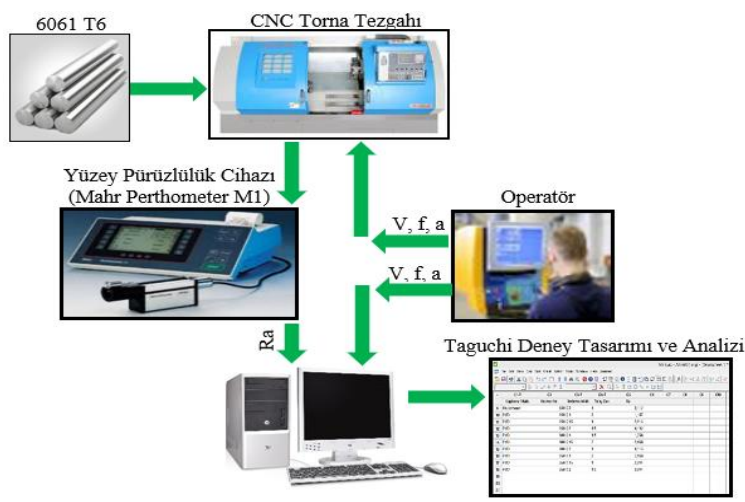

\section{DENEY TASARIMI (EXPERIMENTAL DESIGN)}

Taguchi yöntemi, mühendislik malzemelerinin işlenebilirliğinin belirlenmesinde deney sayısını önemli derecede azaltması ve optimum kesme şartlarını belirlemek için basit, verimli ve sistematik bir çözüm sunmaktadır [12,13]. En iyi işlenmiş yüzeyin belirlenmesinde $\mathrm{S} / \mathrm{N}$ oranı analizinden yararlanılmıştır. S/N oranlarına bağlı olarak en küçük Ra değerlerinin hesaplanmasında Eşitlik 1'de verilen “en küçük en iyidir" denklemi kullanılmıştır [14]. İşleme parametrelerinin her bir seviyesi için $\mathrm{S} / \mathrm{N}$ oranları hesaplanmıştır.

$$
\mathrm{S} / \mathrm{N}=-10 \log \left(\frac{1}{n} \sum_{i=1}^{n} y_{i}^{2}\right)
$$

İşlenmiş yüzeyin kalitesini doğrudan etkileyecek olan etkin kesme parametrelerinin belirlenmesi gerekmektedir. Bu amaçla kesici takım PVD yöntemi ile TiB2 kaplamalı ve kaplamasız, Vc, f ve a dikkate alınacak kontrol faktörleri olarak seçilmiştir. Tablo 2'de tornalama deneyleri için seçilen kontrol faktörleri ve seviyeleri gösterilmektedir. İşleme parametrelerinin etkisini analiz etmek ve optimum kesme parametrelerini belirlemek için L18 $\left(2^{1} \times 3^{3}\right)$ dizinine göre deneyler tasarlanmıştır.

\section{DENEY SONUÇLARI VE ANALIZ (EXPERIMENT RESULTS AND ANALYSIS)}

\section{1. $\mathrm{S} / \mathrm{N}$ oranlarının analizi (Analysis of $S / \mathrm{N}$ Ratios)}

Taguchi yöntemi kullanılarak oluşturulan deney tasarımına göre kontrol faktörlerinin optimizasyonunda Sinyal-Gürültü $(\mathrm{S} / \mathrm{N})$ oranlarından yararlanıldı. En iyi işlenmiş yüzeyin belirlenmesinin, imalat endüstrisine maliyet ve ürün kalitesinin geliştirilmesi açısından büyük katkı sağlayacağ düşünülmektedir. Tablo 3'de yüzey pürüzlülüğü (Ra) için $\mathrm{S} / \mathrm{N}$ oranları verilmiştir. Tornalama deneyleri sonucunda işlenmiş yüzey pürüzlülük değerlerinin ortalaması $1.87 \mu \mathrm{m}$ ve $\mathrm{S} / \mathrm{N}$ oranlarının ortalaması $3.713 \mathrm{~dB}$ olarak hesaplanmıştır.

Şekil 2. Deneysel yöntem (Experimental method)

Tablo 2. Kesme parametreleri ve seviyeleri (Cutting parameters and levels)

\begin{tabular}{lcccc}
\hline Kontrol faktörleri & Sembol & Seviye I & Seviye II & Seviye III \\
\hline Kesici Takım Kaplaması & A & Kaplamasız & Kaplamalı & \\
Vc $(\mathrm{m} / \mathrm{min})$ & B & 250 & 300 & 350 \\
$\mathrm{f}(\mathrm{mm} / \mathrm{dev})$ & $\mathrm{C}$ & 0.1 & 0.15 & 0.2 \\
$\mathrm{a}(\mathrm{mm})$ & D & 1 & 1.5 & 2 \\
\hline
\end{tabular}


Tablo 3. Deney sonuçları ve $\mathrm{S} / \mathrm{N}$ oranları (Test results and $\mathrm{S} / \mathrm{N}$ ratios)

\begin{tabular}{|c|c|c|c|c|c|c|}
\hline \multirow[b]{2}{*}{$\begin{array}{c}\text { Deney } \\
\text { No }\end{array}$} & \multicolumn{4}{|c|}{ Kontrol Faktörleri } & \multirow[b]{2}{*}{$\begin{array}{l}\text { Yüzey Pürüzlülük } \\
\text { Değeri Ra }(\mu \mathrm{m})\end{array}$} & \multirow[b]{2}{*}{$\begin{array}{c}\text { S/N Oranı } \\
\text { (dB) }\end{array}$} \\
\hline & $\begin{array}{c}\text { A } \\
\text { Kaplama }\end{array}$ & $\begin{array}{c}\text { B } \\
\text { Kesme } \\
\text { Hızı }\end{array}$ & $\begin{array}{c}\text { C } \\
\text { İlerleme } \\
\text { Hızı }\end{array}$ & $\begin{array}{c}\text { D } \\
\text { Talaş } \\
\text { Derinliği }\end{array}$ & & \\
\hline 1 & Kaplamasız & 250 & 0.1 & 1 & 0.605 & 4.364893 \\
\hline 2 & Kaplamasız & 250 & 0.15 & 1.5 & 1.127 & -1.03848 \\
\hline 3 & Kaplamasız & 250 & 0.2 & 2 & 2.033 & -6.16275 \\
\hline 4 & Kaplamasız & 300 & 0.1 & 1 & 0.46 & 6.744843 \\
\hline 5 & Kaplamasız & 300 & 0.15 & 1.5 & 1.094 & -0.78035 \\
\hline 6 & Kaplamasız & 300 & 0.2 & 2 & 1.978 & -5.92453 \\
\hline 7 & Kaplamasız & 350 & 0.1 & 1.5 & 0.62 & 4.152166 \\
\hline 8 & Kaplamasız & 350 & 0.15 & 2 & 1.364 & -2.69629 \\
\hline 9 & Kaplamasız & 350 & 0.2 & 1 & 2.112 & -6.49388 \\
\hline 10 & Kaplamalı & 250 & 0.1 & 2 & 1.167 & -1.34142 \\
\hline 11 & Kaplamalı & 250 & 0.15 & 1 & 2.213 & -6.89963 \\
\hline 12 & Kaplamalı & 250 & 0.2 & 1.5 & 4.192 & -12.4484 \\
\hline 13 & Kaplamalı & 300 & 0.1 & 1.5 & 1.058 & -0.48971 \\
\hline 14 & Kaplamalı & 300 & 0,15 & 2 & 2.468 & -7.8469 \\
\hline 15 & Kaplamalı & 300 & 0.2 & 1 & 4.115 & -12.2874 \\
\hline 16 & Kaplamalı & 350 & 0.1 & 2 & 0.868 & 1.229605 \\
\hline 17 & Kaplamalı & 350 & 0.15 & 1 & 2.241 & -7.00884 \\
\hline 18 & Kaplamalı & 350 & 0.2 & 1.5 & 3.944 & -11.9187 \\
\hline
\end{tabular}

Tablo 4. Yüzey pürüzlülüğü için S/N yanıt tablosu (S/N response table for surface roughness)

\begin{tabular}{lllll}
\hline Seviyeler & \multicolumn{4}{c}{ Kontrol Faktörleri } \\
\cline { 2 - 5 } & $\mathrm{A}$ & $\mathrm{B}$ & $\mathrm{C}$ & $\mathrm{D}$ \\
\hline$R a$ & & & & \\
\hline 1 & -0.8705 & -3.9210 & 2.4434 & -3.5967 \\
2 & -6.5568 & -3.4307 & -4.3784 & -3.7539 \\
3 & - & -3.7893 & -9.2060 & -3.7904 \\
Delta & 5.6863 & 0.4903 & 11.6493 & 0.1937 \\
\hline
\end{tabular}

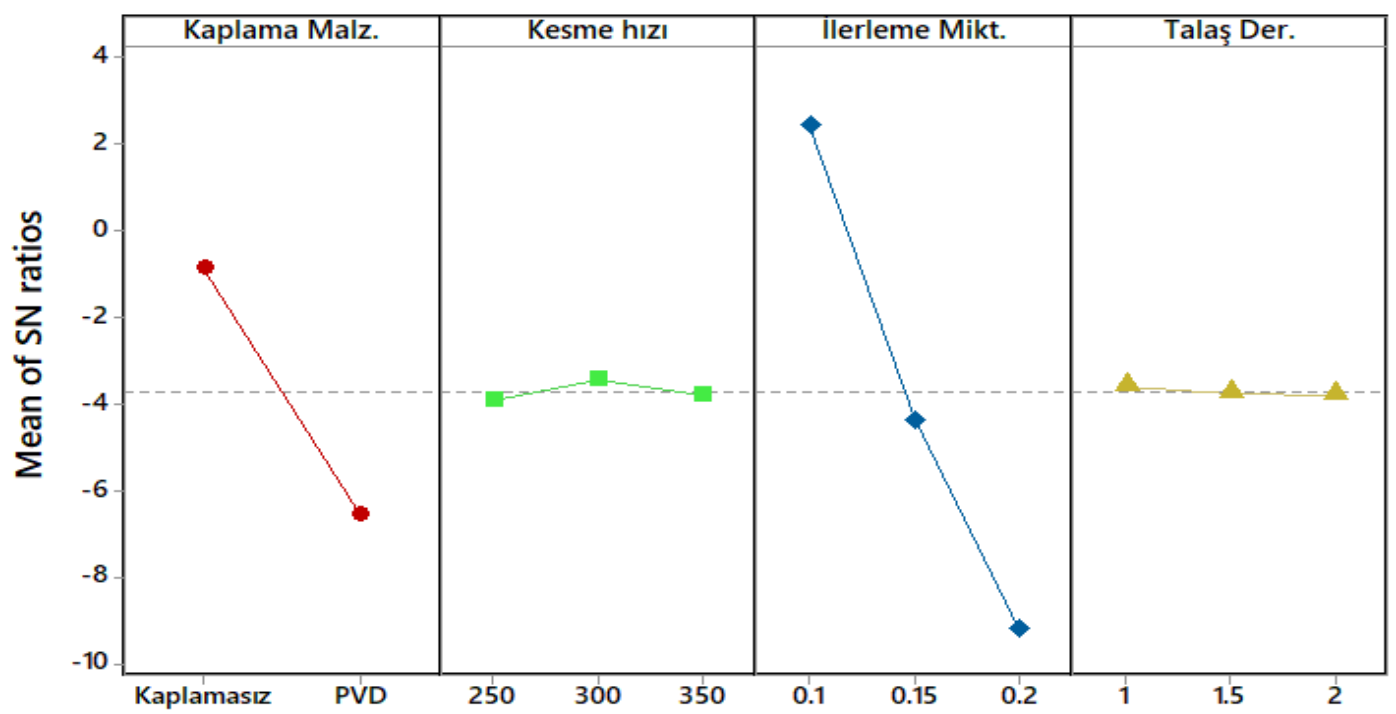

Signal-to-noise: Smaller is better

Şekil 3. Yüzey pürüzlülüğü için kontrol faktörlerinin seviye değerleri (Level values of control factors for surface roughness) 
Kontrol faktörlerinin yüzey pürüzlülüğü üzerindeki etkisi $\mathrm{S} / \mathrm{N}$ yanıt tablosu kullanılarak analiz edilmiştir. Tablo 4'de yüzey pürüzlülüğü için $\mathrm{S} / \mathrm{N}$ yanıt tablosu verilmiştir. Şekil 3'de yüzey pürüzlülüğü için kontrol faktörlerinin seviye değerleri gösterilmektedir. Yüzey pürüzlülüğünün en küçük değeri için kontrol faktörlerinin en iyi seviyeni en büyük $\mathrm{S} / \mathrm{N}$ oranı göstermektedir. Optimum yüzey
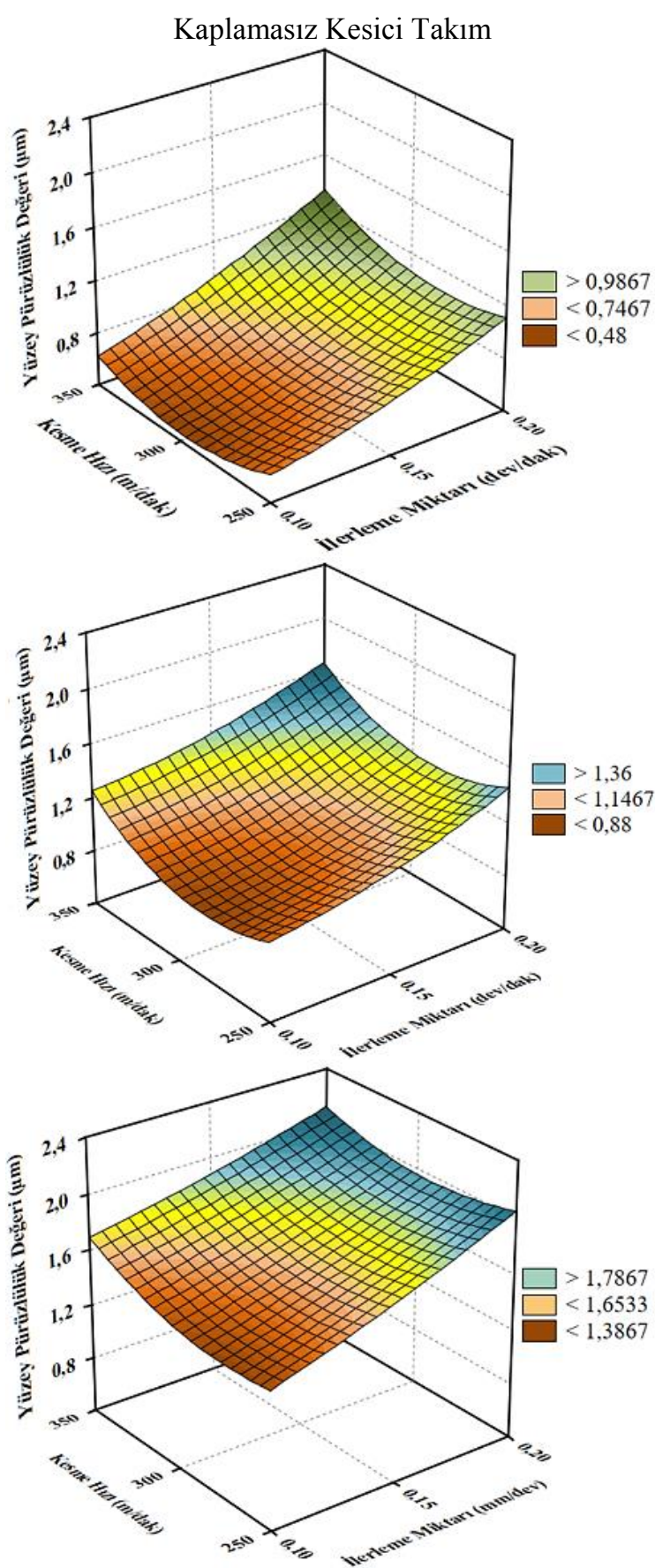

pürüzlülüğü $(\mathrm{Ra})$ için kontrol faktörleri ve seviyeleri A (seviye $1, \mathrm{~S} / \mathrm{N}=0.87$ ), B (seviye $2, \mathrm{~S} / \mathrm{N}=3.43$ ), C (seviye $1, \mathrm{~S} / \mathrm{N}=2.44$ ) ve $\mathrm{D}$ (seviye $1, \mathrm{~S} / \mathrm{N}=3.59$ ) olarak belirlenmiştir. Optimum Ra değeri kaplamasız karbür kesici takımla, $300 \mathrm{~m} / \mathrm{min}$ kesme hızında, 0.1 $\mathrm{mm} / \mathrm{dev}$ ilerleme miktarında ve $1 \mathrm{~mm}$ talaş derinliğinde $0.46 \mu \mathrm{m}$ olarak belirlenmiştir.
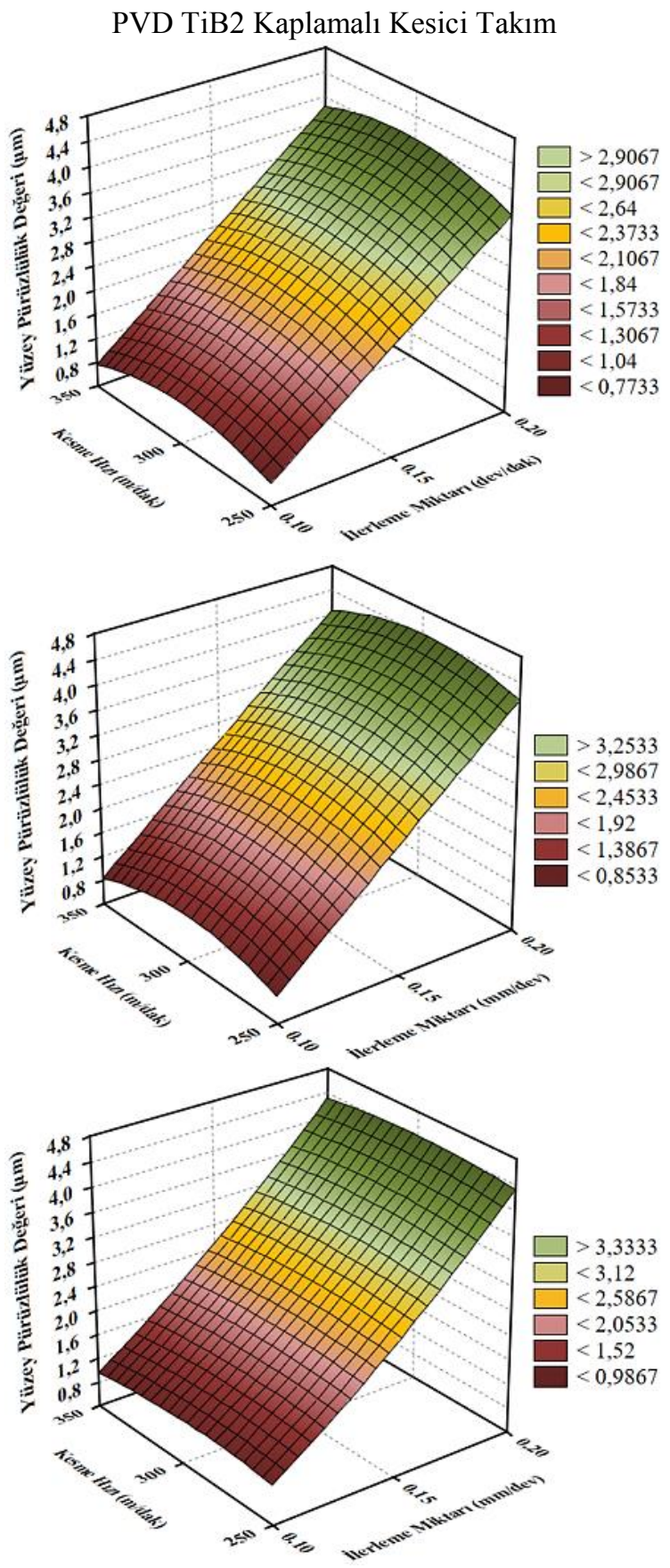

Şekil 4. Kesme parametrelerinin Ra üzerine etkisi a) $1 \mathrm{~mm}$ b) $1.5 \mathrm{~mm}$ c) $2 \mathrm{~mm}$ (The effect of cutting parameters on Ra) 


\subsection{Deney Sonuçlarının Değerlendirilmesi \\ (Evaluation of Experiment Results)}

Kaplamasız ve TiB2 kaplamalı kesici takımlarla yapılan tornalama deneyleri sonucunda elde edilen yüzey pürüzlülüğündeki değişimler Şekil 4'de görülmektedir. Şekil 4 incelendiğinde, kesici takım kaplamasına bağlı olarak yüzey pürüzlülük değerleri değişmiştir. Kaplamasız kesici takımlarla yapılan deneylere göre TiB2 kaplı kesici takımlarla yapılan deneylerde yüzey pürüzlülük değerlerinin yaklaşık olarak \% 120 arttığı belirlenmiştir. Sünek malzemelerin işlenmesinde kullanılan kesici takımlarda talaş açısının büyük ve takım kenarının keskin olması istenir. Kesici takım kaplaması takım geometrisinde bu keskinliği azalttığı için yüzey pürüzlülüğü artmaktadır. En düşük yüzey pürüzlülüğü değeri kaplamasız takımlarla, $300 \mathrm{~m} / \mathrm{min}$ kesme hızında $0.1 \mathrm{~mm} / \mathrm{dev}$ ilerleme miktarında ve $1 \mathrm{~mm}$ talaş derinliğinde yapılan işleme deneyinde $0.46 \mu \mathrm{m}$ ölçülmüştür.

En yüksek yüzey pürüzlülüğü değeri de TiB2 kaplamalı kesici takımlarla $250 \mathrm{~m} / \mathrm{min}$ kesme hızında $0.2 \mathrm{~mm} / \mathrm{dev}$ ilerleme miktarında ve $1.5 \mathrm{~mm}$ talaş derinliğinde yapılan işleme deneyinde $4.115 \mu \mathrm{m}$ ölçülmüştür. Kesme hızının artmasıyla oluşan yüksek kesme sıcaklarında malzeme yapışma eğilimine girerek

Tablo 5. Yüzey pürüzlülüğü için varyans analiz sonuçları (Variance analysis results for surface roughness)

\begin{tabular}{lllllll}
\hline $\begin{array}{l}\text { Kontrol } \\
\text { Faktörleri }\end{array}$ & $\begin{array}{l}\text { Serbestlik } \\
\text { Derecesi }\end{array}$ & $\begin{array}{l}\text { Kareler } \\
\text { Toplamı }\end{array}$ & $\begin{array}{l}\text { Kareler } \\
\text { Ortalaması }\end{array}$ & F Değeri & P Değeri & Katkı Oranı \% \\
\hline Ra & & & & & & \\
\hline A & 1 & 6.5679 & 6.56790 & 41.00 & 0.000 & 27.18 \\
B & 2 & 0.0035 & 0.00174 & 0.01 & 0.989 & 0.014 \\
C & 2 & 15.5312 & 7.76562 & 48.48 & 0.000 & 64.28 \\
D & 2 & 0.4570 & 0.22849 & 1.43 & 0.285 & 1.89 \\
Error & 10 & 1.6019 & 0.16019 & - & - & 6.62 \\
Total & 17 & 24.1615 & & & & 100 \\
\hline
\end{tabular}

\section{SONUC (CONCLUSIONS)}

Bu çalışmada, AA6061 alaşımının tornalanmasında yüzey pürüzlülüğü üzerinde kesici takım kaplamasının ve işleme parametrelerinin etkisinin analizi ve optimizasyonu yapılmıştır. Yapılan çalışmada elde edilen sonuçlar aşağıda belirtilmiştir.

$\checkmark$ Optimum yüzey pürüzlülük değeri, A kesici takım kaplamas1, kaplamasız (Seviye 1), B kesme hız1 $300 \mathrm{~m} / \mathrm{min}$ (Seviye 2), C ilerleme miktarı 0.1 $\mathrm{mm} / \mathrm{dev}$ (seviye 1) ve $\mathrm{D}$ talaş derinliği $1 \mathrm{~mm}$ (seviye 1) bu parametrelerle yapılan işleme deneyi yüzey pürüzlülüğü değerlerinde düzensizliğe neden olmuştur. Ayrıca yüksek kesme hızlarında kesici takım ucunda oluşan küçük kırılmalar yüzey pürüzlülüğü değerlerinde artışa neden olmuştur [15].

\subsection{Varyans Analizi (Analysis of Anova)}

Kesici takım kaplamasının, kesme hızının, ilerleme miktarının ve talaş derinliğinin yüzey pürüzlülüğü üzerindeki etkisini belirlemek için istatiksel bir metot olan varyans analizi kullanılmıştır. Yapılan bu analiz \% 95 güven seviyesinde gerçekleştirilmiştir. Yüzey pürüzlülük değerleri (Ra) için Anova sonuçları Tablo 5'de sunulmuştur. Kontrol faktörlerinin çıktı üzerindeki etkisinin istatiksel olarak ifade edilebilmesi için önem seviyesi $(\mathrm{P})$ ve katkı oranının belirlenmesinde F değerleri dikkate alınır. Kontrol faktörlerinin çıktı üzerinde istatiksel olarak anlamlı olabilmesi için P değeri 0.05 'den küçük olmalı ve en fazla etki eden faktörün belirlenmesinde ise $\mathrm{F}$ değeri en büyük olan kontrol faktörü kabul edilmektedir [16]. Varyans (Anova) analiz sonuçlarına göre yüzey pürüzlülüğü üzerinde en etkin parametre \% 64.28 katkı oranı ile ilerleme miktarı olmuştur. Tornalama deneylerinde elde edilen sonuçlar ile istatiksel analiz sonuçları karşılaştırıldığında birbirlerini doğrular niteliktedir. 
kaplaması yüzey pürüzlülüğü değerlerinde artışa neden olmuştur.

$\checkmark$ Daha sonra yapılacak çalışmalar için kesici takım kaplamasının, kesme kuvvetleri üzerinde etkisinin araştırılmasında kesme sıcaklığının ölçülmesi ve kesme kuvvetleri ile ilişkilendirilmesi önerilmektedir.

\section{KAYNAKLAR (REFERENCES)}

[1] A. R. Jeshvaghani, H. Zohdi, H. R. Shahverdi, M. Bozorg, S. M. M. Hadavi, "Influence of multi-step heat treatments in creep age forming of 7075 aluminum alloy: Optimization for springback, strength and exfoliation corrosion," Materials Characterization, Vol. 73, pp. 8-15, November 2012. Doi: 10.1016/j.matchar.2012.05.012

[2] E. Kilickap, "Modeling and optimization of burr height in drilling of Al-7075 using Taguchi method and response surface methodology," Int. J. Adv. Manuf. Technol., Vol. 49, pp. 911-923, January 2010. Doi: 10.1007/s00170-009-2469-x

[3] H. Demir, S. Gündüz, "The effects of aging on machinability of 6061 aluminium alloy," Materials and Design, Vol. 30, pp. 1480-1483, May 2009. Doi: 10.1016/j.matdes.2008.08.007

[4] P. Jayaramana, K. L. Mahesh, "Multi-response optimization of machining parameters of turning AA6063 T6 aluminium alloy using grey relational analysis in taguchi method," Procedia Engineering, Vol. 97, pp. 197-204, 2014. Doi: 10.1016/j.proeng.2014.12.242

[5] M. Kurt, Y. Kaynak, E. Bağcı, "Evaluation of drilled hole quality in Al 2024 alloy," Int. J. Adv. Manuf. Technol., Vol. 37, pp. 1051-1060, July 2008. Doi:10.1007/s00170-007-1049-1

[6] P. G. Benardos, G. C. Vosniakos, "Predicting surface roughness in machining: A review," International Journal of Machine Tool and Manufacturing, Vol. 43, pp. 833-844, May 2007. Doi: $10.1007 / \mathrm{s} 00170-007-1049-1$

[7] T. Kivak, G. Uzun, E. Ekici, "An experimental and statistical evaluation of the cutting parameters on the machinability of hadfield steel" Gazi University Journal of Science, Vol. 29, pp. 9-17, 2016.

[8] H.B. Ulaş, "Experimental Determination of Cutting Forces and Surface Roughness when Turning 50CrV4 Steel (SAE 6150) and Modelling with the
Artificial Neural Network Approach," Transactions of the Indian Institute of Metals, Vol. 67, pp. 869879, December 2014. DOI 10.1007/s12666-0140410-y

[9] B. Rajeswari, K. S. Amirthagadeswaran, "Experimental investigation of machinability characteristics and multi-response optimization of end milling in aluminium composites using RSM based grey relational analysis," Measurement, Vol. 105, pp. 78-86, July 2017. Doi: 10.1016/j.measurement.2017.04.014

[10] A. R. Gonçalves, B. M. Silva, "Influence of copper content on 6351 aluminum alloy machinability," Procedia Manufacturing, Vol. 1, pp. 683-695, 2015. Doi: 10.1016/j.promfg.2015.09.014

[11] M. S. Ranganath, Vipin, R. S. Mishra, Prateek, Nikhil, "Optimization of surface roughness in CNC turning of aluminium 6061 using Taguchi techniques," International Journal of Modern Engineering Research (IJMER), Vol. 5, pp. 42-50, 2015.

[12] K. Palanikumar, "Experimental investigation and optimisation in drilling of GFRP composites," Measurement, Vol. 44, pp. 2138-2148, December 2011. Doi: 10.1016/j.measurement.2011.07.023

[13] I. Asilturk, H. Akkus, "Determining the effect of cutting parameters on surface roughness in hard turning using the Taguchi method," Measurement, Vol. 44, pp. 1697-1704, November 2011. Doi: 10.1016/j.measurement.2011.07.003

[14] N. Masmiati, A. A. D. Sarhan, "Optimizing cutting parameters in inclined end milling for minimum surface residual stress - Taguchi approach," Measurement, Vol. 60, pp. 267-275, January 2015.2 Doi: 10.1016/j.measurement.2014.10.002

[15] I. Ciftci, "Machining of austenitic stainless steels using CVD multi-layer coated cemented carbide tools," Tribology International, Vol. 39, pp. 565-569, June $2006 . \quad$ Doi: 10.1016/j.triboint.2005.05.005

[16] M. Akgün, H. Demir, \& İ. Çiftçi, "Mg2Si partikül takviyeli magnezyum alaşımlarının tornalanmasında yüzey pürüzlülüğünün optimizasyonu," Politeknik Dergisi, Cilt. 21, pp. 645650, Aralık 2017. Doi: 10.2339/politeknik.385481 


\section{Barış ÖZLÜ}

Barış ÖZLÜ, 1978 yılında Konya'da doğmuştur. 2005 yllında Zonguldak Karaelmas Üniversitesi Karabük Teknik Eğitim Fakültesi Makine Eğitimi Bölümü'nden mezun oldu. Aynı yıl Zonguldak Karaelmas Üniversitesi Fen Bilimleri Enstitüsü Makine Eğitimi Bölümü'nde yüksek lisans eğitimine başlamış ve 2007 yılında yüksek lisans eğitimini tamamlamıştır. 2007 ve 2010 yılları arasında özel sektörde imalat ve ARGE sorumlusu olarak farklı firmalarda çalışmıştır. 2011 yılında Amasya Üniversitesi'nde öğretim görevlisi olarak başlamış olduğu akademik kariyerine, 2012 y1lından itibaren Aksaray Üniversitesi Aksaray Teknik Bilimler Meslek Yüksekokulunda devam etmektedir. 2014 yılında Karabük Üniversitesi Fen Bilimleri Enstitüsü İmalat Mühendisliği Bölümünde Doktora eğitimine başlamış ve 2019 yılında doktora eğitimini tamamlamıştır. CNC ve üniversal takım tezgâhları, sicak dövme, mühendislik malzemelerinin işlenebilirliği, kesici takım teknolojisi, $\mathrm{CAD} / \mathrm{CAM} / \mathrm{CAE}$ alanlarında çalışmalarını sürdürmektedir.

\section{Mahir AKGÜN}

Mahir AKGÜN, 1990 yllında Yozgat ilinde doğmuştur. Lisans eğitimini, 2011 yılında Karabük Üniversitesi, Teknik Eğitim Fakültesi Makine Eğitim Bölümünden ve 2018 yılında Aksaray Üniversitesi, Makine Mühendisliği Bölümü'nden mezun olarak tamamlamıştır. 2010 ve 2013 yılları arasında Ankara ilinde çeşitli savunma sanayi firmalarında CAD/CAM uzmanı olarak çalışmıştır. 2013 yılında Karabük Üniversitesi, Fen Bilimleri Enstitüsü, İmalat Mühendisliği Anabilim Dalı'ndan yüksek lisans eğitimini tamamladı. Aynı yıl Aksaray Üniversitesi, Teknik Bilimler Meslek Yüksekokulu'na Öğretim Görevlisi olarak göreve başladı ve halen görevine devam etmektedir. Karabük Üniversitesi, Fen Bilimler Enstitüsü, İmalat Mühendisliği Anabilim dalında doktora eğitimini sürdürmekte ve CNC takım tezgâhları, CAD/CAM/CAE ve mühendislik malzemelerinin işlenebilirliği alanlarında çalışmaktadır.

\section{Halil DEMİR}

Halil DEMİR, 1969 y1lında Malatya'da doğmuştur. 1994 y1lında Gazi Üniversitesi Teknik Eğitim Fakültesi Makine Eğitimi Bölümü'nden mezun olmuştur. Gazi Üniversitesi Fen Bilimleri Enstitüsü Makine Eğitimi Bölümü'nde yüksek lisans ve doktora eğitimlerini, sırasıyla 1998 ve 2003 yıllarında tamamlamıştır. 1999 yılında Gazi Üniversitesi'nde araştırma görevlisi olarak başlamış olduğu akademik kariyerini, 2004-2010 y1lları arasında Karabük Üniversitesi Teknik Eğitim Fakültesi Makine Eğitimi Bölümü'nde Yrd. Doç. Dr olarak devam ettirmiştir. 2010-2016 y1lından itibaren Karabük Üniversitesi Teknoloji Fakültesi İmalat Mühendisliği Bölümü'nde Doç. Dr. ve 2016'dan itibaren akademik kariyerini Prof. Dr. olarak sürdürmektedir. Geleneksel ve geleneksel olmayan imalat yöntemleri, takım tezgâhları, kesici takım teknolojileri, mühendislik malzemelerinin işlenebilirliği, deney tasarımı ve optimizasyon alanlarında çalışmaktadır. 